\title{
Joseph Murray (1919-2012): First transplant surgeon
}

\author{
Siang Yong $\underline{\operatorname{Tan}}^{1}$, MD, JD, Jason Merchant $^{2}$, MD
}

In fact, basic scientists were pessimistic about the feasibility of human transplantation. For example, in his book The Biological Basis of Individuality, Dr Leo Loeb categorically stated that transplantation between individual humans would never be possible. Although his thesis was accepted as dogma by some, it did not seem irrefutable to me. Surgeons, by nature, tend to be optimists.

- Joseph Murray

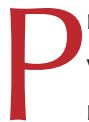
rior to the 1900s, it seemed that human organ transplantation would be an impossible feat. Several attempts had been made but all had ended in rejection of the donor kidney. Thanks to the groundbreaking work of Dr Joseph Murray in the 1950s and 1960s, renal transplants now take place throughout the world on a daily basis. Murray was the first surgeon to successfully perform renal transplantation, first in identical twins, then in non-identical twins and, finally, using a cadaveric donor. For his pioneering work concerning organ transplantation in the treatment of human diseases, Murray was awarded the Nobel Prize in Physiology or Medicine in 1990.

\section{I B E R A L B E G I N N I N G S} Murray was born in Milford, Massachusetts, United States, a town 30 miles southwest of Boston, Massachusetts, on 1 April 1919. Influenced by his family doctor, Murray knew he wanted to become a surgeon at a young age. He attended College of the Holy Cross, a small liberal arts college in Massachusetts. Murray

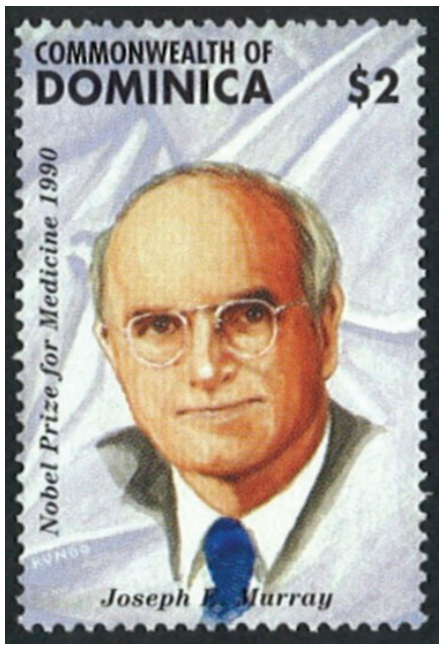
the initial trip back to the United States, Woods began the long road to recovery, which required covering the burned areas with cadaveric skin grafts. The donor grafts survived long enough for Woods' own healthy skin to be harvested and used as autografts to cover the burned areas. Over the course of 24 operations, the surgical team was able to remodel his eyelids, nose, mouth and hands, with Woods surviving the operations and eventually becoming a successful businessman. Murray would later recall, "The questions raised and lessons learned in trying to help Charles would determine the course of the rest of my professional life." Murray's first exposure to the field of reconstructive surgery led him to marvel at how relatively simple surgeries could have a profound impact on a person's life. The case also ignited his lifelong passion for correcting terrible physical deformities and spawned another interest, transplantation - for Murray had seen for the first time how the tissue of one person could be used to save the life of another.

To further Murray's interest in transplantation, Dr James Barrett Brown, chief of surgery at Valley Forge General Hospital at the time, shared his own experiences in treating burn patients. He observed that the closer the donor's genetic relationship to the patient was, the more resistant the graft was to rejection. Dr Brown had previously grafted skin between identical twins and documented the first case of permanent survival of the donor tissue. Murray himself also noted experiments by Prof Thomas Gibson and Sir Peter Medawar that reported how the transplantation of a second skin allograft from the same donor was rejected more rapidly than the first, implying that an immunologic process his reasoning as follows: "Assuming I'd receive ample science in medical school, I took the minimum of chemistry, physics and biology." He attended Harvard Medical School and subsequently did his surgical internship at the Peter Bent Brigham Hospital in Boston, Massachusetts.

A CHANCE ENCOUNTER Towards the end of his internship year, Murray was drafted into military service for World War II and was stationed at Valley Forge General Hospital, a major plastic surgery centre in Pennsylvania. He spent most of his time caring for the casualties of the war. One such unfortunate individual was Charles Woods, a 22-year-old pilot who had sustained burns over $70 \%$ of his body, including his face and hands, while flying a fuel transport plane over India. After surviving was the cause of transplant rejection.

After the war was over, Murray returned to Boston to continue training in plastic reconstructive surgery, but increasingly began pursuing his transplant interests. He realised that overcoming the immunologic barrier in organ transplantation would be a monumental challenge. Many of his peers discounted his pursuit, believing that the problem of immune rejection was insurmountable. At the same time, as Murray was aware that no cure for patients with end-stage renal disease then existed, he proceeded with experiments to determine whether a transplanted kidney would function properly if immune rejection could be avoided. He performed renal transplants on dogs, which Murray not only perfected vascular and ureteral anastomoses did not develop severe transplant rejections, unlike humans.

${ }^{1}$ Emeritus Professor of Medicine, University of Hawaii, Honolulu, USA, ${ }^{2}$ Research carried out during 1st year residency, Transitional Residency Program, University of Hawaii, Honolulu, USA

Correspondence: Prof Tan Siang Yong, 2226 Liliha Street, Suite B-104, Honolulu, HI 96817, USA. siang@hawaii.edu 
but also optimised site selection for housing the donor kidney. The techniques he mastered during that period are still the basic surgical methods used today.

UNIQUE OPPORTUNITY In 1954, Richard Herrick, a patient with a healthy twin brother named Ronald, presented with renal failure to Peter Bent Brigham Hospital. It did not take long for Murray to raise the idea of a successful renal transplant between the genetically identical brothers. After establishing successful cross-skin grafting, his team began preparations for the transplantation, even as Murray realised that they were confronting a major ethical dilemma. Performing a major live donor operation, in effect removing a healthy kidney for no personal benefit and possibly causing harm, was something that had never been done before. The team consulted various medical and religious leaders on whether this broke Hippocrates' oath "First, do no harm". After due discussion, all parties involved agreed that surgery should proceed because of its life-saving potential. Surgery took place on 23 December 1954, with Murray leading the recipient's surgical team and Dr J Hartwell Harrison leading the donor's surgical team. Both operations proved uneventful; postoperatively, the transplanted kidney functioned immediately. Richard would survive long enough to get married and have two children before succumbing to cardiac failure eight years later. Ronald had no major complications and lived over 50 years after the surgery. While this sentinel event showed that kidney transplantation surgery was technically possible, it nonetheless did not address or solve the underlying issue of immunologic incompatibility.

BREAKTHROUGH Murray used several techniques to prevent graft rejections in genetically non-identical hosts. He first used total body irradiation, followed by bone marrow replacement, which was initially successful in an operation between two non-genetically identical twins. The 24-year-old recipient, John Riteris, lived 29 years after the transplant. However, the approach proved unreliable in suppressing the recipient's immune system, and the results could not be consistently reproduced. In 1959, a major breakthrough occurred when 6-mercaptopurine was used by Dr Robert S Schwartz and Dr William Dameshek to prevent antibody production in rabbits against human serum albumin. Murray initially used 6-mercaptopurine in dogs and later azathioprine, a less toxic immunosuppressant developed by British researcher Roy Calne, which resulted in a marked increase in allograft survival.

In 1961, Murray performed the first unrelated kidney transplant in humans using immunosuppressive therapy. The transplant functioned well, but the patient died from drug toxicity. In his second attempt, Murray was initially able to control and reverse the rejection phenomenon by starting azathioprine, which was later discontinued when leucopenia developed. Rejection of the kidney occurred soon after and azathioprine was readministered, with subsequent improvement in renal function. However, the patient died of a severe infection thereafter. The third patient, 23-year-old Mel Doucette, survived for over a year following what is considered the first successful renal allograft. As protocols for renal transplantation were refined and new immunosuppressant agents became available, survival rates increased dramatically, leading to the establishment of national donor programmes and the International Renal Transplant Registry. After the success of renal transplants, other organ transplants soon followed, including those of the liver and heart.

FOLLOWING HIS HEART Notwithstanding his pioneering work in human transplantation, Murray's true passion was still reconstructive surgery. In choosing between the two, he decided to step down as chief of transplant surgery at Peter Bent Brigham Hospital in 1971 to focus on paediatric reconstructive surgery, becoming the chief of plastic surgery at the Boston Children's Hospital Medical Center in Boston. He developed procedures for repairing birth defects and treating paediatric burn victims. In 1986, Murray suffered a stroke and, following a quick recovery, retired to spend time with his wife, six children and many grandchildren. To cap off his illustrious career, Murray received the Nobel prize in Physiology or Medicine in 1990, together with Dr Edward Donnall Thomas, for his contributions to the advancement of transplantation medicine. A friend and colleague of Murray, Dr Francis Moore, joked, "Joe's the only guy who ever won a Nobel Prize for pursuing a hobby." In 2001, Murray wrote his autobiography, Surgery of the Soul: Reflections on a Curious Career, which recounts his encounter with Charles Woods as well as other patients who had guided his career.

\section{BIBLIOGRAPHY}

- Barry JM, Murray JE. The first human renal transplants. J Urol 2006; 176:888-90.

- Murray J. Interview with Dr Joseph Murray (by Francis L Delmonico). Am J Transplant 2002; 2:803-6.

- Friedrich MJ. Joseph Murray, MD-transplantation pioneer. JAMA 2004; 292:2957-8.

- Merrill JP, Murray JE, Harrison JH, Guild WR. Successful homotransplantation of the human kidney between identical twins. J Am Med Assoc 1956; 160:277-82.

- Merrill JP, Murray JE, Harrison JH, et al. Successful homotransplantation of the kidney between nonidentical twins. N Engl J Med 1960; 262:1251-60.

- Murray JE, Merrill JP, Harrison JH, Wilson RE, Dammin GJ. Prolonged survival of human-kidney homografts by immunosuppressive drug therapy. $\mathrm{N}$ Engl J Med 1963; 268:1315-23.

- Murray JE. The first successful organ transplants in man. J Am Coll Surg 2005; 200:5-9.

- Murray JE. Surgery of the Soul: Reflections on a Curious Career. 1st ed. Sagamore, MA: Science History Publications, 2001.

- The Nobel Foundation. The Nobel Prize in Physiology or Medicine. Available at: https://www.nobelprize.org/prizes/medicine. Accessed March 10, 2019. 